\title{
The effects of catastrophic thinking about pain on attentional interference by pain: No mediation of negative affectivity in healthy volunteers and in patients with low back pain
}

\author{
G Crombez $\mathrm{PhD}^{1}$, C Eccleston $\mathrm{PhD}^{2}$, A Van den Broeck MSc ${ }^{3}$, \\ B Van Houdenhove $\mathrm{MD}^{3}$, L Goubert MSc ${ }^{1}$
}

G Crombez, C Eccleston, A Van den Broeck, B Van Houdenhove, L Goubert. The effects of catastrophic thinking about pain on attentional interference by pain: No mediation of negative affectivity in healthy volunteers and in patients with low back pain. Pain Res Manage 2002;7(1):31-39.

BACKGROUND: Previous studies have shown that catastrophic thinking about pain enhances attentional interference in healthy volunteers.

OBJECTIVE: To investigate whether the attentional effects of pain catastrophizing can be accounted for by the more general predisposition of negative affectivity.

METHODS: Sixty-seven pain-free students participated in the first experiment, and 33 patients with chronic low back pain par- ticipated in the second experiment. In both experiments, participants performed an auditory reaction time task while being exposed to a series of threatening electrocutaneous stimuli. Retardation in reaction times to auditory probes during pain was taken as an index of the attentional interruption by pain. Participants also completed self-report instruments of negative affectivity and pain catastrophizing.

RESULTS: In both experiments, pain catastrophizing enhanced attentional interference by pain. This effect was most pronounced immediately after the onset of the electrocutaneous

${ }^{1}$ Ghent University, Ghent, Belgium; ${ }^{2}$ University of Bath, Bath, United Kingdom; ${ }^{3}$ Leuven University, Leuven, Belgium

Correspondence: Dr Geert Crombez, Ghent University, Henri Dunantlaan 2, B-9000 Gent, Belgium. Telephone +32-9-264-64-61,

fax+32-9-264-64-89, e-mail geert.crombez@rug.ac.be

Received for publication December 20, 2000. Accepted February 27, 2001 
stimulus. The effect remained after controlling for the effects of negative affectivity.

CONCLUSIONS: Catastrophic thinking about pain enhances attentional interruption by pain in normal samples, as well as in clinical samples of patients with chronic back pain. This effect is specific to pain catastrophizing and cannot be explained by the more general disposition of negative affectivity.

Key Words: Anxiety; Attention; Catastrophizing; Fear; Negative affectivity; Pain

\section{Pensées dramatiques au sujet de la douleur et troubles de l'attention causés par la douleur : aucune influence de la tonalité affective négative chez les sujets en santé et les patients souffrant de lombalgie}

CONTEXTE : Des études ont montré que les pensées dramatiques au sujet de la douleur augmentent les troubles de l'attention chez les sujets en santé.
OBJECTIF : Vérifier si l'effet attentionnel des pensées dramatiques au sujet de la douleur peut faire partie des prédispositions plus générales de la tonalité affective négative.

MÉTHODE : Soixante-sept étudiants non souffrants ont participé à la première expérience et 33 patients souffrant de lombalgie chronique ont participé à la deuxième expérience. Dans les deux groupes, on a demandé aux sujets d'exécuter une tâche liée au temps de réaction à un son tout en étant exposés à une série de stimulus électrocutanés menaçants. Le retard du temps de réaction aux émissions sonores durant la douleur a été traité comme un indice de l'interruption de l'attention par la douleur. Les participants ont également rempli des questionnaires d'auto-déclaration sur la tonalité affective négative et les pensées dramatiques.

RÉSULTATS : Dans les deux groupes, les pensées dramatiques ont augmenté les troubles de l'attention causés par la douleur. L'effet a surtout été marqué immédiatement après le début des stimulus électrocutanés et il s'est fait persistant même après rajustement pour tenir compte des effets de la tonalité affective négative.

CONCLUSION : Les pensées dramatiques au sujet de la douleur augmentent les troubles de l'attention causés par la douleur chez les sujets en santé ainsi que chez les patients souffrant de lombalgie chronique. L'effet est propre à la dramatisation de la pensée et ne peut s'expliquer par les dispositions plus générales de la tonalité affective négative.
$\mathrm{P}$ ain has a high priority for attention over other competing stimuli within environments. Pain functions to interrupt ongoing behaviour and to capture attention $(1,2)$. A number of experimental and clinical studies have explored the antecedents and the consequences of the interruption of attention by pain (3-5). From these studies, the threat of pain has emerged as a promising concept (2). The present paper contributes to the further development of this concept by exploring the specific role of catastrophic thinking about pain in both laboratory and clinical settings.

Catastrophic thinking about pain is a negative painrelated cognition and can be considered to be an instantiation of the high threat value of pain. Although the criteria have never been explicitly stated, pain catastrophizing has been broadly defined as an exaggerated negative orientation toward actual and anticipated pain experiences (6). In support of this view, a number of studies have demonstrated a close relationship between catastrophic thinking and pain-related fear. For example, Chaves and Brown (7) found that dental patients who had catastrophic thoughts during a stressful dental procedure reported high anxiety. In a clinical sample of patients with chronic low back pain, catastrophic thinking was related to the fear of (re)injury and the fear of back-straining movements $(8,9)$. Furthermore, healthy volunteers with high catastrophic thinking about pain were shown to be more fearful during the threat of high intensity pain than those with low catastrophic thinking about pain (10).

Catastrophic thinking about pain has also been related to an inability to divert attention away from pain. Sullivan et al (6), for example, found that catastrophizing about pain largely reflected an inability to suppress or divert attention away from pain-related thoughts (eg, "I can't seem to keep it out of my mind"). Heyneman et al (11) reported experimental evidence suggesting that catastrophizers are impaired in their ability to use a distraction coping strategy. Crombez et al (9) reported experimental results demonstrating that healthy volunteers with catastrophic thinking about pain were less able to direct attention away from a highly threatening somatic stimulus. These results converge upon the idea that the threat value of pain is important in mediating attention toward pain arising from within complex environments (2). This idea is also consistent with recent theories about attentional bias toward threat in nonpainful situations. In a critical review of the attentional bias literature regarding clinical and nonclinical anxiety, Mogg and Bradley (12) argued that attentional bias toward stimuli in these situations is a normal and functional process that is best explained by the threat value of these stimuli.

A largely unexplored issue pertains to the role of negative affectivity as an explanation for the attentional effects of catastrophic thinking about pain. Negative affectivity can be broadly defined as a personality trait characterized by low mood and the predisposition to appraise personal and emotional situations as threatening (13). According to Watson and Pennebaker (13), people with high negative affectivity are hypervigilant for all forms of internal and external threat. It is, therefore, reasonable to assume that the inability to direct attention away from pain by pain catastrophizers may be an instantiation of hypervigilance to threat in people with high negative affectivity. In line with this assumption, studies have found a significant relationship between catastrophic thinking about pain and negative affectivity. In two studies with healthy volunteers as participants, Crombez et al (9) observed that those classified as reporting high catastrophic thinking about pain also had higher scores on a self-report questionnaire of negative affectivity. In a clinical sample of patients with chronic low back pain, catastrophic thinking about pain was significantly related to the disposition to experience negative 
affect (10). Also, Sullivan et al (6) found a significant relationship between negative affectivity and pain catastrophizing. In a further analysis, these authors showed that, at least with regard to the prediction of pain, pain catastrophizing is distinct from negative affectivity. However, because almost all of this evidence relies on correlational analyses and selfreport measures, experimental research may be more compelling in further disentangling and distinguishing the basic processes in these two constructs.

The main aim of the present study was to investigate whether the attentional effects of pain in people with high catastrophic thinking about pain are present when controlling for the effects of negative affectivity. This question was addressed by using the primary task procedure reported by Crombez et al (9 [study 2]). In this procedure, participants were instructed to ignore pain while performing an auditory discrimination task. Participants were instructed to respond as quickly as possible to the tone probes without sacrificing accuracy. At the same time, they were exposed to a series of low intensity electrocutaneous stimuli (ES), which they were led to believe "worked by exciting pain fibres". The retardation in reaction times to the tone probes during exposure to the ES was taken as a measure of attentional interference by pain. In that study, participants with high catastrophic thinking about pain showed more attentional interference by the ES than students with low catastrophic thinking about pain. This effect was most pronounced immediately after the onset of the ES.

The results of two experimental studies are reported in the present article. In the first experiment, participants were healthy volunteers. In the second experiment, participants were patients with low back pain. In line with the results of Crombez et al (9), it was expected that:

- participants with high catastrophic thinking about pain would show more attentional interference during the ES than participants with low catastrophic thinking about pain;

- the effect of catastrophic thinking about pain would be most pronounced immediately after the onset of the ES; and

- the attentional interference effects would remain even after controlling for the effects of negative affectivity.

\section{EXPERIMENT 1}

\section{Subjects and methods}

Participants: Sixty-seven students (19 men and 48 women between the ages of 17 and 26 years [mean \pm SD $18.87 \pm 1.61$ years]) participated in the experiment. No participant was excluded because of the number of errors in the auditory discrimination task. The number of errors varied between 0 and $4(0.84 \pm 1.05)$. All participants gave informed consent and were instructed that they were free to terminate the experiment at any time.

Apparatus and material: An AC stimulator delivered the ES with an internal frequency of $50 \mathrm{~Hz}$, an instantaneous rise and fall time, and a duration of $1500 \mathrm{~ms}$. The stimuli were delivered through a pair of standard silver/silver chloride electrodes ( $1 \mathrm{~cm}$ diameter) attached to the left forearm and filled with KY Jelly (Johnson \& Johnson, USA). During the experimental phase, a stimulus of $0.63 \mathrm{~mA}$ was employed. A pilot study revealed that an ES of that intensity was judged as mildly aversive and tolerable. The internal speaker of the computer emitted high $(1000 \mathrm{~Hz})$ and low $(250 \mathrm{~Hz})$ pitch tones (200 ms duration).

After the experiment, participants received a number of questionnaires. The Pain Catastrophizing Scale - Dutch Version (PCS) $(6,9)$ is a 13 -item scale used for both nonclinical and clinical populations. Participants reflect on past painful experiences and indicate the degree to which they experienced particular thoughts or feelings during pain on a five-point scale (eg, "I can't seem to keep it out of my mind", "I feel I can't stand it any more"). The Dutch version has been shown to have good reliability and validity in a student population (10) and in a clinical population (9). The median PCS score was 16 in a student population (9). The Negative Emotionality Scale (NEM) is a trait measure of negative affectivity; it is a 14-item, two-point scale derived from Tellegen's Multidimensional Personality Questionnaire (14). Those who score high on the NEM describe themselves as nervous, apprehensive, irritable, overly sensitive and emotionally labile. The Dutch version has been shown to be reliable and valid (15).

Finally, a number of self-report instruments were specifically developed for this study to investigate the differential effects of pain catastrophizing upon the pain experience. Graphic Rating Scales (GRSs) of $10 \mathrm{~cm}$ in length were used (16). The unpleasantness of the ES was reported using a numerical GRS (anchored by $+5=$ pleasant and $-5=$ unpleasant). The intensity of the ES was reported using a verbal GRS (anchored by the adjectives 'weak', 'moderate', 'intense', 'enormous' and 'unbearable'). Using a numerical GRS (anchored by the adjectives 'not at all', 'weak', 'moderate', 'strong' and 'very strong'), participants rated the extent to which each of the following sensations was experienced during exposure to the ES: pricking, boring, flickering, electric and cutting. For statistical analyses, the number of variables was reduced, resulting in an intensity-affect scale and a flickering scale (9). Intensity-affect scores were obtained by adding the intensity, pricking, boring and cutting scores, and subtracting the (un)pleasantness score (minimum score -5 , maximum score 45). Flickering scores were obtained by adding the flickering and electric scores (minimum score 0 , maximum score 20).

\section{Procedure \\ Pre-experimental phase: To familiarize the participants with the ES and the experimental procedure, they were given a series of stimuli with increasing intensity. These stimuli were delivered through the electrodes attached to the forearm. After presentation of the $0.63 \mathrm{~mA}$ stimulus, the participants were asked to evaluate their experiences using all GRSs. The participants also practised the tone dis-}




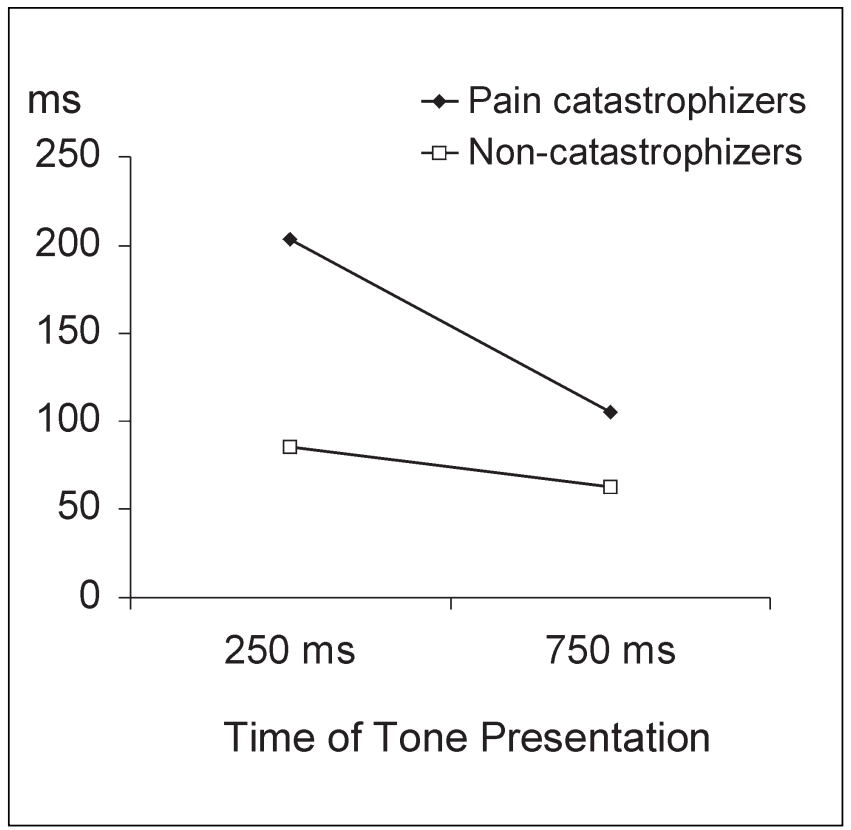

Figure 1) The mean interference scores ( $m s)$ for tones presented at time $250 \mathrm{~ms}$ and time $750 \mathrm{~ms}$ for pain catastrophizers and noncatastrophizers in a sample of healthy volunteers

crimination task. They were instructed to respond to the tones as quickly as possible without sacrificing accuracy. Participants responded to the tones with the right hand by pressing a two-buttoned console. Participants practised the task (15 low and 15 high pitch tones) without any ES. The interstimulus interval between the tones (stimulus-stimulus interval) varied between $1200 \mathrm{~ms}$ and $1800 \mathrm{~ms}$ (mean $1500 \mathrm{~ms}$ ).

To control for demand characteristics, participants were unaware of the true nature of the experiment. They were led to believe that the main interest of the experiment was the putative influence of a distraction coping strategy on a psychophysiological measure of stimulus perception, in particular, the electrodermal response. Participants were further led to believe that electrocutaneous stimulation is a conventional way of investigating pain sensitivity. More specifically, they were informed that pain fibres were stimulated directly and that most people found this stimulation unpleasant and painful.

Experimental phase: Participants were instructed to pay close attention to the tones and to respond to the tones as quickly as possible without sacrificing accuracy. They were informed that, after the experimental phase, the ES had to be rated on all GRSs. However, participants were explicitly instructed to ignore the ES.

The intensity of the ES was $0.63 \mathrm{~mA}$ for all participants. They were not informed when these stimuli would be applied. During half of the ES, a tone probe was presented at one of two temporal positions, resulting in two different types of experimental events. Time $250 \mathrm{~ms}$ - during two trials of the ES, a tone was presented $250 \mathrm{~ms}$ after stimulus onset. Time $750 \mathrm{~ms}$ - during two other trials of the ES, a tone was presented at $750 \mathrm{~ms}$ after stimulus onset. Four ES without tone probes were presented to avoid the ES becoming a predictor of tones. Baseline - forty-four tones were presented in the absence of the ES. The reaction time to the tone presented immediately before each ES was used as the baseline reaction time.

The ES were presented in an individually determined random sequence, with the restriction that, in each experimental phase, each type of experimental event was presented twice. Of the 48 tones presented, half were high in pitch. The interstimulus interval for the tones varied between 1200 and 1800 ms (mean 1500 ms). No more than three consecutive tone trials consisted of a tone with the same pitch. The computer recorded reaction times and discrimination errors.

\section{RESULTS}

\section{Self-reports}

In this sample, the mean PCS score was $16.06 \pm 8.37$ and the mean NEM score was $6.61 \pm 3.72$. The correlation between the PCS and the NEM was significant $(r=0.40$, $\mathrm{P}<0.001$ ). The median split (the medium PCS score in the student population was 16) resulted in a group of pain catastrophizers $(\mathrm{n}=29$, mean $24.10 \pm 5.39)$ and in a group of noncatastrophizers $(n=38$, mean 9.92 \pm 3.55$)$. Pain catastrophizers $(7.93 \pm 3.66)$ reported more negative affectivity (NEM) than noncatastrophizers $(7.93 \pm 3.41, \mathrm{t}[64]=2.71$, $\mathrm{P}<0.01$ ).

An ANOVA of the intensity-affect scores revealed a significant main effect of phase $(F[1,64]=51.77$, mean squared error $[\mathrm{MSE}]=23.11, \mathrm{P}<0.001)$. The main effect of group $(F[1,64]=0.34, M S E=68.31)$ and the interaction between group and phase $(F[1,64]=0.49, \mathrm{MSE}=23.11)$ were not significant. The effect of phase occurred because the component score was lower at the experimental phase (mean 13.94) than at the pre-experimental phase (mean 20.05). An ANOVA of the flickering scores revealed a main effect of phase $(\mathrm{F}[1,33]=11.28, \mathrm{MSE}=5.19, \mathrm{P}<0.001)$ but no significant main effect of group $(F[1,63]=2.35, \mathrm{MSE}=26.62)$ nor a significant interaction between group and phase $(F[1,63]=0.01, M S E=5.19)$. The main effect of phase indicated that the flickering scores were lower at the experimental phase (mean 7.96) than at the pre-experimental phase (mean 9.32).

\section{Behavioural measure of attentional interference} Only $1.3 \%$ of the reaction times (RT) were missing or invalid (RT less than $150 \mathrm{~ms}$ or greater than $2000 \mathrm{~ms}$ ). Valid RTs for each type of experimental event were averaged across the two trials of each experimental event. To obtain interference scores, the RTs during the ES trials were expressed as changes in scores from the baseline measures. These interference scores are illustrated in Figure 1. In the group of pain catastrophizers, the RT detriment in the auditory discrimination task was larger than in the group of 
noncatastrophizers. As expected, this effect was most pronounced immediately after stimulus onset.

Results of a $2 \times 2$ (group [pain catastrophizers versus noncatastrophizers] $\times$ time of tone presentation [time $250 \mathrm{~ms}$ versus time $750 \mathrm{~ms}]$ ) ANOVA supported these observations. The main effect of group was significant $(F[1,65]=6.95$, $\mathrm{MSE}=30342, \mathrm{P}<0.01)$. The effect of time of tone presentation was also significant $(F[1,65]=5.00, M S E=23913$, $\mathrm{P}<0.05$ ), indicating that task interference at time $250 \mathrm{~ms}$ (mean $144 \mathrm{~ms}$ ) was larger than at time $750 \mathrm{~ms}$ (mean $84 \mathrm{~ms}$ ). The effect of group $\times$ time of tone presentation was not significant $(F[1,65]=2.02, M S E=23913)$. Because of the authors' interest in the temporal pattern of interference, a priori tests were used to investigate further the temporal pattern of interference. At time $250 \mathrm{~ms}$, the interference in the group of pain catastrophizers was significantly larger than the interference in the group of noncatastrophizers $(\mathrm{F}[1,65]=7.67, \mathrm{MSE}=30061, \mathrm{P}<0.01)$. At time $750 \mathrm{~ms}$, the difference in interference between pain catastrophizers and noncatastrophizers was not significant $(F[1,65]=1.19$, $\mathrm{MSE}=24193, \mathrm{P}=0.30$ ).

In a next step, the effect of pain catastrophizing was investigated after partialling out the effects of negative affectivity. Results of a $2 \times 2$ (group $\times$ time of tone presentation) ANCOVA with the NEM score as a covariate revealed effects similar to those seen with the results of the ANOVA. The main effect of group was significant $(\mathrm{F}[1,63]=5.10, \mathrm{MSE}=31135, \mathrm{P}<0.05)$. The main effects of time of tone presentation $(\mathrm{F}[1,63]=1.73, \mathrm{MSE}=24517$ and the group $\times$ time of tone presentation interaction $(F[1,63]=1.861, M S E=24517)$ were not significant. The NEM score as a covariate had no effect on the interference scores (effect of NEM score: $F[1,63]=0.302$, MSE $=31135$; effect of NEM score $\times$ time of tone presentation: $F[1,63]=1.86, M S E=24517)$. Finally, at time $250 \mathrm{~ms}$, the effect of pain catastrophizing remained significant after partialling out the effect of negative affectivity $(F[1,63]=6.06$, $\mathrm{MSE}=30879, \mathrm{P}<0.05)$. At time $750 \mathrm{~ms}$, the effect of pain catastrophizing remained nonsignificant $(F[1,63]=0.69$, MSE=24773).

\section{DISCUSSION}

The results of experiment 1 are similar to those reported previously (9). Healthy volunteers with a high frequency of catastrophic thoughts about pain showed more attentional interference on the primary task during the ES than participants with a low frequency of catastrophic thoughts about pain. This effect was most pronounced immediately after the onset of the ES. In contrast with the results of Crombez et al (9), we did not observe a significant effect on the reported intensity of the ES. It was expected that participants with high catastrophic thinking about pain would rate the ES as more intense than would participants with low catastrophic thinking about pain. It was reasoned that the inability to divert attention away from pain in the pain catastrophizers would amplify the intensity of the ES. We do not have a clear explanation for this discrepancy.
As expected, healthy volunteers with a high frequency of catastrophic thinking reported more negative affectivity than those with a low frequency of catastrophic thinking about pain. Of particular interest to this study is the observation that the enhanced attentional interference during ES in the pain catastrophizers remained, even after controlling for the effects of negative affectivity.

Experiment 2 investigated whether these results could be reproduced in a clinical sample of patients with low back pain. Because the procedure of experiment 2 is similar to that of experiment 1 , only differences in procedure are discussed.

\section{Patients and methods}

\section{EXPERIMENT 2}

Patients: Thirty-five patients with nonspecific back pain were recruited from the orthopedic consultation unit at the University Hospital Pellenberg, Belgium. Three patients were excluded because of too much missing data (more than $25 \%$ ), leaving valid data for 32 patients (11 men and 21 women between the ages of 18 and 60 years, mean age $36.56 \pm 12.07)$. Seventy-eight per cent of the 32 patients were married or cohabiting. Almost half of the patients (44\%) had a postsecondary education. Twelve patients $(37.5 \%)$ did not have paid employment. The average time since the onset of pain was $57.5 \pm 67.72$ months (range six to 300 months).

\section{Procedure}

Materials and procedures were almost identical to those described in experiment 1 . Most of the procedural differences were related to the differences in populations. After the experiment, patients received more questionnaires, including the PCS - Dutch Version, the Multidimensional Pain Inventory - Dutch Version Part 1 (MPI-DV) (17), and the trait form of the State-Trait Anxiety Inventory - Dutch version (STAI-trait) $(18,19)$. Part 1 of the MPI-DV consists of five scales: pain severity (three items), interference with daily life due to pain (11 items), perceived life control (four items), affective distress (three items) and social support (three items). Negative affectivity was measured by the trait form of the STAI - a 20-item instrument designed to assess the general inclination to experience anxiety (18). Patients are asked to rate on a four-point scale how accurate the statements are about oneself (eg, "I am jittery"). According to Watson and Pennebaker (13), the STAI-trait is a valid measure of negative affectivity. This was confirmed by the strong correlation $(\mathrm{r}=0.75)$ between the Dutch version of the STAI-trait and the Dutch version of the NEM in a Flemish sample of students (15).

The self-report scales used to assess the experience during the experiment were identical to those used in experiment 1 . In addition, patients rated the current pain intensity using a 101-point numerical rating scale of intensity, in which patients were asked to express their present pain intensity on a scale of 0 to $100(0=$ no pain, $100=$ worst imaginable pain). 


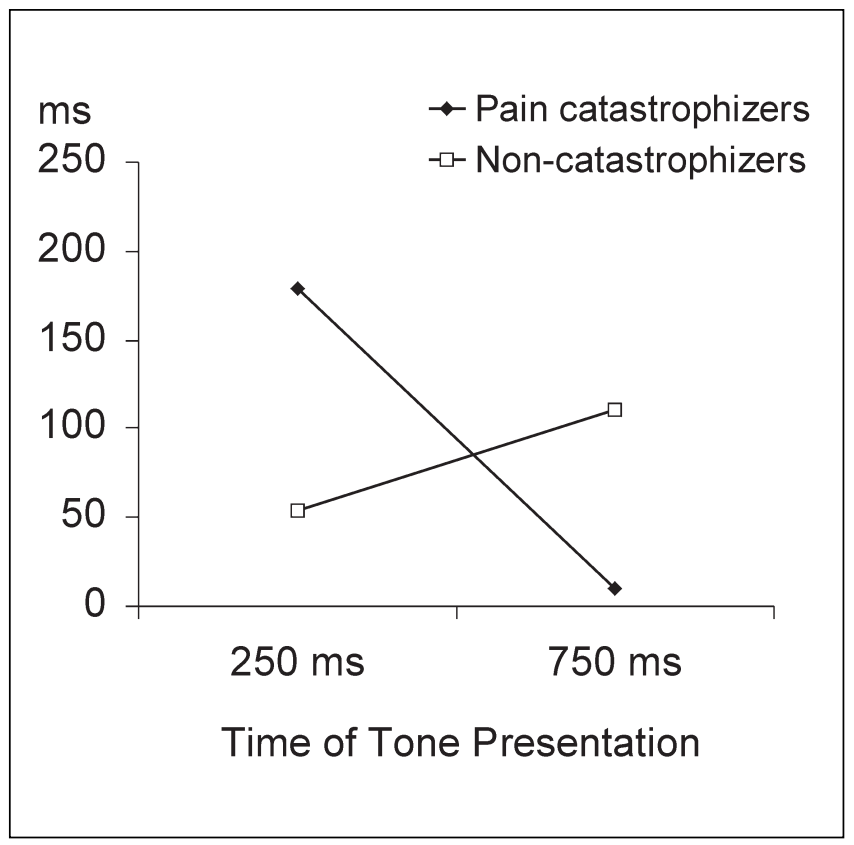

Figure 2) The mean interference scores ( $\mathrm{ms}$ ) for tones presented at time $250 \mathrm{~ms}$ and time $750 \mathrm{~ms}$ for pain catastrophizers and noncatastrophizers in a sample of patients with chronic low back pain

The characteristics and the number of the ES and the tones were identical to those in experiment 1 . However, a pilot study revealed that some patients had difficulty with the pace of the tone presentations. Therefore, for experiment 2, response-stimulus intervals (time between the onset of the response and the onset of the next tone probe) were used instead of the stimulus-stimulus intervals (time between the onset of the tone probe and the onset of the next tone probe) that were used in experiment 1 . Response-stimulus intervals varied from 700 to $1300 \mathrm{~ms}$ (mean $1000 \mathrm{~ms}$ )

\section{RESULTS}

\section{Self-reports}

In comparison with the MPI-DV results of a patient group entering a cognitive-behavioural rehabilitation program (17), the severity of the pain complaints in the present patient sample was moderate to average. The average scores were $3.60 \pm 1.43$ for the pain severity scale (average score of the comparison group 4.50); $3.56 \pm 1.45$ for the interference scale (average score of the comparison group 4.52); $3.21 \pm 1.12$ for the affective distress scale (average score of the comparison group 3.24$) ; 3.44 \pm 1.0$ for the life control scale (average score of the comparison group 3.12); and $3.43 \pm 1.95$ for the social support scale (average score of the comparison group 4.78). The mean pain intensity was low at the time of testing $(19.87 \pm 11.08)$. The mean score for STAI-trait was $44 \pm 9.08$, which is just below the norms for clinical anxiety (mean STAI-trait for clinical anxiety 48.08). The mean score of the PCS was $23.56 \pm 7.83$, and the median score was 24 . A median split resulted in a group of pain catastrophizers $(n=13$, mean $30.46 \pm 5.19)$ and a group of noncatastrophizers ( $\mathrm{n}=19$, mean 18.84 \pm 5.45$)$. Pain catastrophizers (mean 47.37 \pm 9.17 ) reported more negative affectivity than noncatastrophizers (mean $47.85 \pm 7.75, \mathrm{t}[64]=2.71, \mathrm{P}<0.01)$.

Results of an ANOVA of the intensity-affect scores revealed a significant main effect of phase $(F[1,28]=5.81$, $\mathrm{MSE}=16.02, \mathrm{P}<0.001)$. The main effect of group $(F[1,28]=0.48, M S E=85.05)$ and the interaction between group and phase $(\mathrm{F}[1,28]=0.10, \mathrm{MSE}=16.02)$ were not significant. The effect of phase occurred because the component score was lower at the experimental phase (mean 4.60) than at the pre-experimental phase (mean 7.07). Results of an ANOVA of the flickering scores revealed no significant effects (phase: $\mathrm{F}[1,27]=0.13, \mathrm{MSE}=8.47$; group: $\mathrm{F}[1,27]=0.15$, MSE $=30.35$; interaction between group and phase: $F[1,27]=0.05, \mathrm{MSE}=8.47$ ).

Behavioural measure of attentional interference: Less than $3 \%$ of the RTs were missing or invalid (RT less than $150 \mathrm{~ms}$ or greater than $2000 \mathrm{~ms}$ ). As in experiment 1, interference scores were calculated (Figure 2). In the group of pain catastrophizers, the detriment in the auditory discrimination task was larger than in the group of noncatastrophizers at time $250 \mathrm{~ms}$. At time $750 \mathrm{~ms}$, the interference pattern seemed to reverse. Results of a $2 \times 2$ (group [pain catastrophizers versus noncatastrophizers] $\times$ time of tone presentation [time $250 \mathrm{~ms}$ versus time $750 \mathrm{~ms}$ ]) ANOVA partly supported these observations. The main effect of group was not significant $(F[1,30]=0.075, \mathrm{MSE}=28146)$. The effect of time of tone presentation was also not significant $(F[1,30]=1.36, M S E=34759)$. The group $\times$ time of tone presentation was, however, significant $(F[1,30]=5.70$, $\mathrm{MSE}=34759, \mathrm{P}<0.001)$. Because of the authors' interest in the temporal pattern of interference, a priori tests were used to investigate further the temporal pattern of interference. At time $250 \mathrm{~ms}$, the interference in the group of catastrophizers was significantly larger than the interference in the group of noncatastrophizers $(F[1,30]=4.04, M S E=29927$, $\mathrm{P}<0.05$ ). At time $750 \mathrm{~ms}$, the difference in interference between pain catastrophizers and noncatastrophizers was not significant $(F[1,30]=2.41, \mathrm{MSE}=32987, \mathrm{P}>0.10)$.

In a next step, the effect of pain catastrophizing was investigated after partialling out the effects of negative affectivity. Results of a $2 \times 2$ (group $\times$ time of tone presentation) ANCOVA with the STAI-trait score as covariate revealed similar effects as the ANOVA. The main effects of group $(F[1,29]=0.29, \mathrm{MSE}=28504)$ and the time of tone presentation $(F[1,29]=0.01, \mathrm{MSE}=35946)$ were not significant. The effect of group $\times$ time of tone presentation remained significant $(\mathrm{F}[1,29]=4.67, \mathrm{P}<0.05)$. Using the STAI-trait score as a covariate had no effect on the interference scores (effect of STAI-trait score: $F[1,29]=0.62$, $\mathrm{MSE}=28504$; effect of STAI-trait score $\times$ time of tone presentation: $F[1,29]=0.00, M S E=35946)$. Finally, at time $250 \mathrm{~ms}$, the effect of pain catastrophizing remained significant after partialling out the effect of negative affectivity $(\mathrm{F}[1,29]=4.07, \mathrm{MSE}=30731, \mathrm{P}<0.05)$. At time $750 \mathrm{~ms}$, the 
effect of pain catastrophizing remained nonsignificant $(\mathrm{F}[1,29]=1.51, \mathrm{MSE}=33718)$.

\section{DISCUSSION}

The results of experiment 2 were similar to the results of experiment 1 and can be summarized as follows.

- Attentional interference during the ES is enhanced in patients with catastrophic thinking about pain.

- This effect is most marked immediately after the onset of the ES.

- Patients with high catastrophic thinking about pain do not report a higher intensity of the ES during the primary task in comparison with patients with low catastrophic thinking about pain.

- Patients with high catastrophic thinking about pain report more negative affectivity than patients with low catastrophic thinking about pain.

- Finally, the enhanced effect of attentional interference in patients with high catastrophic thinking about pain remained even after controlling for the effects of negative affectivity.

\section{GENERAL DISCUSSION}

The results of two experiments designed to investigate the effects of pain catastrophizing and negative affectivity on attentional interference by pain were reported. The main findings were as follow.

- People with high catastrophic thinking about pain show more attentional interference during electrical stimulation than do people with low catastrophic thinking about pain. This is true for both patients with chronic pain and participants without pain.

- For high pain catastrophizers, this effect of pain on attention is most pronounced at the immediate onset of the threatening ES. This is true for both patients with chronic pain and participants without pain.

- Even after controlling for negative affectivity, the effects of pain on attention for high catastrophizers remain significant. This is true for both patients with chronic pain and participants without pain.

This study offers the first replication of previous findings in this field (9) and, importantly, extends the findings obtained from a healthy student population to a sample of patients with clinically relevant pain. The facilitative effects of catastrophic thinking about pain on the interrup- tive function of pain do not reflect a mechanism employed only by pain-free participants. For both patients with chronic pain and participants without pain, those who are catastrophizing about pain prioritize pain-related stimuli, as measured by the interruption of attention with a primary task paradigm.

Catastrophic thinking about pain is emerging as a key variable in explanations of why people attend repeatedly and often to threatening pain-related stimuli. The specificity of this response was clearly demonstrated in these experiments. Despite the significant association between catastrophizing and negative affectivity, the effects of pain on attention were specific to pain catastrophizing and were not accounted for by negative affectivity (ie, the global disposition to appraise the world and oneself within the world negatively). This was the case in experiment 1 , comprising healthy volunteers and using the NEM (15) as a measure of negative affectivity. This was also the case in experiment 2 , comprising patients with chronic low back pain and using the STAI-trait (18) as a measure of negative affectivity. This finding of the specificity of catastrophizing about pain has a number of theoretical and clinical implications.

First, because the effects of catastrophic thinking are not related to the stable disposition of negative affectivity, it becomes important to investigate how catastrophic thinking about pain develops. We assume that one learns to be fearful of pain and that one learns the relationship between pain-related cues and the experience of pain. However, very little is known about how valence or salience comes to be placed on a specific threat cue such as pain-related stimuli (20). For example, the role of the health care provider in the development of the association between threat and pain is largely unexplored (21).

Second, the function of attentional interference in people with catastrophic thinking may be best explained within a cognitive-affective model of attention to pain proposed by Eccleston and Crombez (2). According to this model, it was argued that attentional interruption by pain is strongly related to an active readiness to escape from a threat to the integrity of the body. Therefore, whether one catastrophizes about pain, or whether one is a high or low catastrophizer may not be important. More important is the context within which one catastrophizes about pain. When pain is escapable, catastrophic thinking may facilitate efficient escape. However, in conditions with limited possibilities of escape, it is important to know to what extent people who catastrophize about pain either disengage from painrelated stimuli, or remain vigilant toward somatic threat and persevere in trying to escape from the uncontrollable aversive event (22).

Third, with closer inspection of the data, one could argue that both participants without pain and patients with clinical pain have no difficulties disengaging from painrelated stimuli. Indeed, the facilitative effects of catastrophic thinking about pain are slight, because in both experiments, the effects only appeared immediately after the onset of the pain-related stimuli. However, further 
study is warranted to investigate the idea that patients with clinical pain have difficulties disengaging their attention from the somatic threat. Although patients with pain who participated in this study had chronic pain, they reported relatively low pain intensity at the time of testing and relatively unimpeded function. Furthermore, difficulties in disengaging attention will probably become more apparent in experiments using experimental stimuli that share maximal sensory characteristics with clinical pain.

Fourth, because attentional interruption by pain is facilitated by its threat value, the use of attentional coping strategies aimed at intentionally distracting attention away from pain may be of little value. It has been demonstrated that those who catastrophize about pain do not benefit from distraction strategies $(9,11)$. More promise may be found in attempts to therapeutically alter the threatening meaning of chronic pain and its consequences (2). For patients with chronic back pain, the threat value of pain may be challenged by a gradual exposure to physical activities that are avoided because of the fear of pain and (re)injury (23). This technique may be effective, not only in extinguishing avoidance behaviour and altering the threat value of pain, but also in diminishing the enhanced attentional interruption by pain (4).

A number of limitations to the present research must be considered. First, in both studies, a median split procedure was used to differentiate between groups with high and low catastrophic thinking about pain, which may have reduced the power to detect group differences. With a larger number of participants, other statistical procedures may be preferred (24). Second, the complaints of the clinical sample were low in comparison with those of a group of patients entering a cognitive-behavioural revalidation program. Although our sample of patients had no difficulties disengaging from pain, it is possible that patients who have more severe complaints might have these problems. Third, in contrast to the

\section{REFERENCES}

1. Price DD. Classical and current theories of pain mechanisms. In: Price DD, ed. Psychological and Neural Mechanisms of Pain. New York: Raven Press, 1988:212-31.

2. Eccleston C, Crombez G. Pain demands attention: a cognitiveaffective model of the interruptive function of pain. Psychol Bull 1999;125:356-66.

3. McCracken LM. "Attention" to pain in persons with chronic pain: a behavioral approach. Behav Ther 1997;28:271-84.

4. Crombez G, Vervaet L, Lysens R, Baeyens F, Eelen P. Avoidance and confrontation of painful back straining movements in chronic back pain patients. Behav Modif 1998;22:62-77.

5. Vlaeyen JWS, Linton SJ. Fear-avoidance and its consequences in chronic musculoskeletal pain: a state of the art. Pain 2000;85:317-32.

6. Sullivan MJL, Bishop SR, Pivik J. The pain catastrophizing scale: development and validation. Psychol Assess 1995; 7:524-32.

7. Chaves JF, Brown JM. Spontaneous cognitive strategies for the control of clinical pain and stress. J Behav Med 1987;10:263-76.

8. Vlaeyen JWS, Kole-Snijders AMJ, Boeren RGB, Van Eek H. Fear of movement (re)injury in chronic low back pain and its relation to behavioural performance. Pain 1995;62:363-72. results of a previous study (9), we did not find that difficulty in diverting attention away from pain in pain catastrophizers resulted in an amplification of the self-reported pain intensity. We do not have a clear explanation for this discrepancy.

\section{CONCLUSIONS}

Catastrophizing about pain facilitates the interruption of attention by pain-related stimuli. This effect is specific to catastrophizing and cannot be explained by negative affectivity or the experience of being a patient with chronic pain. It will be important for the future elaboration of these ideas to learn how a pattern of catastrophic thinking about pain develops and how to diminish its interruptive effects.

\section{ADDENDUM}

Experiment 1 consisted of two extra blocks of ES and tone probes. These blocks were identical to the first block, the results of which are reported in the present article. Statistical analyses of the interference scores in block 2 and block 3, however, revealed no significant effect of pain catastrophizing (block 2: group $F[1,65]=0.36$, group $\times$ time of tone presentation $F[1,65]=1.33$; block 3: group $F[1,65]=2.42$, group $\times$ time of tone presentation $F[1,65]=0.452$ ). Because experiment 2 consisted of only one block, only results of the first block are reported in full detail.

ACKNOWLEDGEMENTS: We thank Ragna Van Vossole, Ilse De Croock and Tessy Verwaest for data collection. We are also indebted to Philippe Lauwerijns and the orthopedic consultation unit at the University Hospital Pellenberg for their referral of patients with low back pain. This study was supported by a research grant (G.0107.98) of the Fund for Scientific Research, Flanders and by a grant of the British-Flemish Academic Research Collaboration Programme (V 7.002.98N). L Goubert is Research Assistant of the Fund for Scientific Research - Flanders (Belgium).
9. Crombez G, Eccleston C, Baeyens F, Eelen P. When somatic information threatens, catastrophic thinking enhances attentional interference. Pain 1998;75:187-98.

10. Crombez G, Vlaeyen JWS, Heuts PHTG, Lysens R. Pain-related fear is more disabling than pain itself: evidence on the role of pain-related fear in chronic back pain disability. Pain 1999;80:329-39.

11. Heyneman N, Fremouw WJ, Gano D, Kirkland F, Heiden L. Individual differences and the effectiveness of different coping strategies for pain. Cogn Ther Res 1990;14:63-77.

12. Mogg K, Bradley BP. A cognitive-motivational analysis of anxiety. Behav Res Ther 1998;36:809-48.

13. Watson D, Pennebaker JW. Health complaints, stress and distress: Exploring the central role of negative affectivity. Psychol Rev 1989;96:234-54.

14. Tellegen A. Brief Manual for the Differential Personality Questionnaire. Unpublished Manuscript. University of Minnesota, 1982.

15. Stegen K, Neujens A, Crombez G, Hermans D, Van de Woestijne KP, Van den Bergh O. Negative affect, respiratory reactivity, and somatic complaints in a $\mathrm{CO}_{2}$ enriched air inhalation paradigm. Biol Psychol 1998;49:109-22.

16. Jensen MP, Karoly P. Self-report scales and procedures for assessing 
pain in adults. In: Turk DC, Melzack R, eds. Handbook of Pain Assessment. New York: The Guilford Press, 1992:135-51.

17. Lousberg R, Van Breukelen GJP, Groenman NH, Schmidt AJM, Arntz A, Winter FAM. Psychometric properties of the Multidimensional Pain Inventory, Dutch language version (MPI-DLV). Behav Res Ther 1999;37:167-82.

18. Spielberger CD, Gorsuch RL, Lushene RE. Manual for the State/Trait Anxiety Inventory. Palo Alto: Consulting Psychologist's Press, 1970.

19. Van der Ploeg HM, Defares P, Spielberger CD. Handleiding bij de Zelf-Beoordelings-Vragenlijst ZBV. Lisse: Swets \& Zeitlinger, 1982.

20. Vansteenwegen D, Crombez G, Baeyens F, Eelen P. Extinction in fear conditioning: effects on startle modulation and evaluative selfreports. Psychophysiology 1998;35:729-36.

21. Rainville J, Bagnall D, Phalen L. Health care providers' attitudes and beliefs about functional impairments and chronic back pain. Clin J Pain 1995;11:287-95.

22. Aldrich S, Eccleston C, Crombez G. Worrying about chronic pain: vigilance to threat and misdirected problem solving. Behav Res Ther 2000;38:457-70.

23. Vlaeyen JWS, de Jong J, Geilen M, Heuts PHTG, Van Breukelen G. Graded exposure in vivo in the treatment of pain-related fear: a replicated single-case experimental design in four patients with chronic low back pain. Behav Res Ther 2001;39:151-66.

24. Maxwell SE, Delaney, HD. Bivariate median splits and spurious statistical significance. Psychol Bull 1993;113:181-90. 


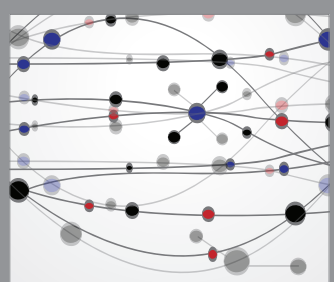

The Scientific World Journal
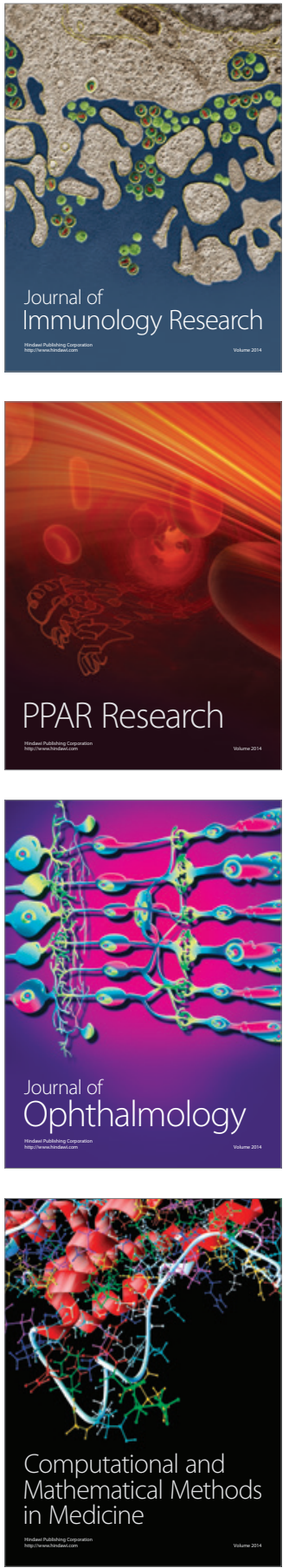

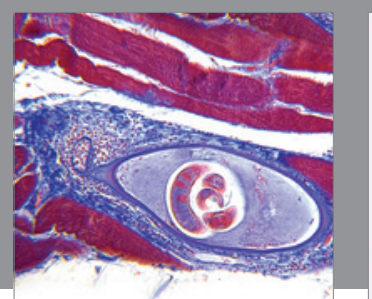

Gastroenterology Research and Practice

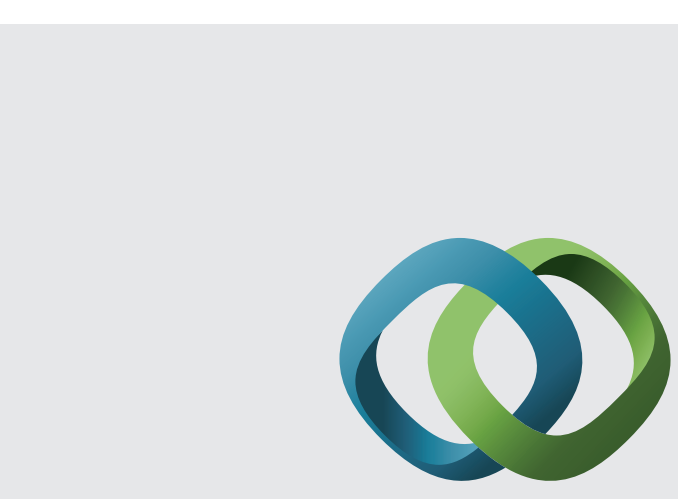

\section{Hindawi}

Submit your manuscripts at

http://www.hindawi.com
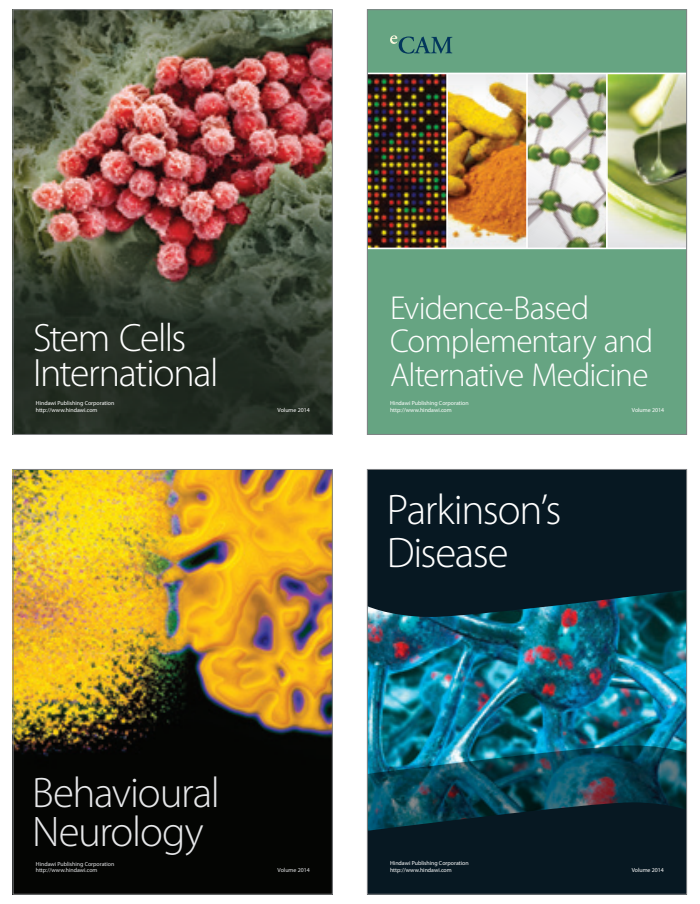
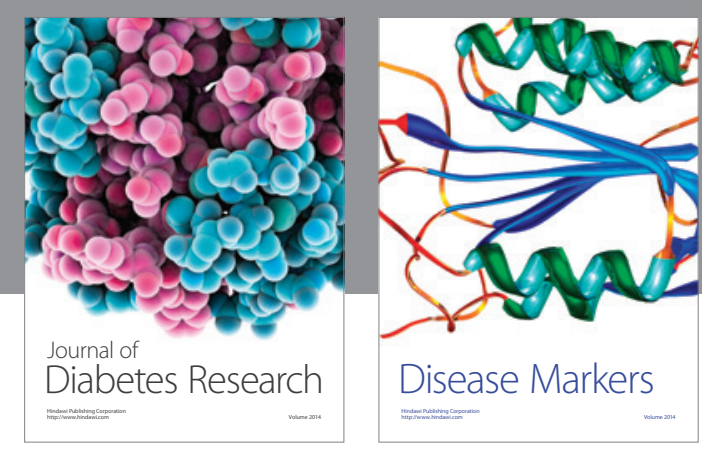

Disease Markers
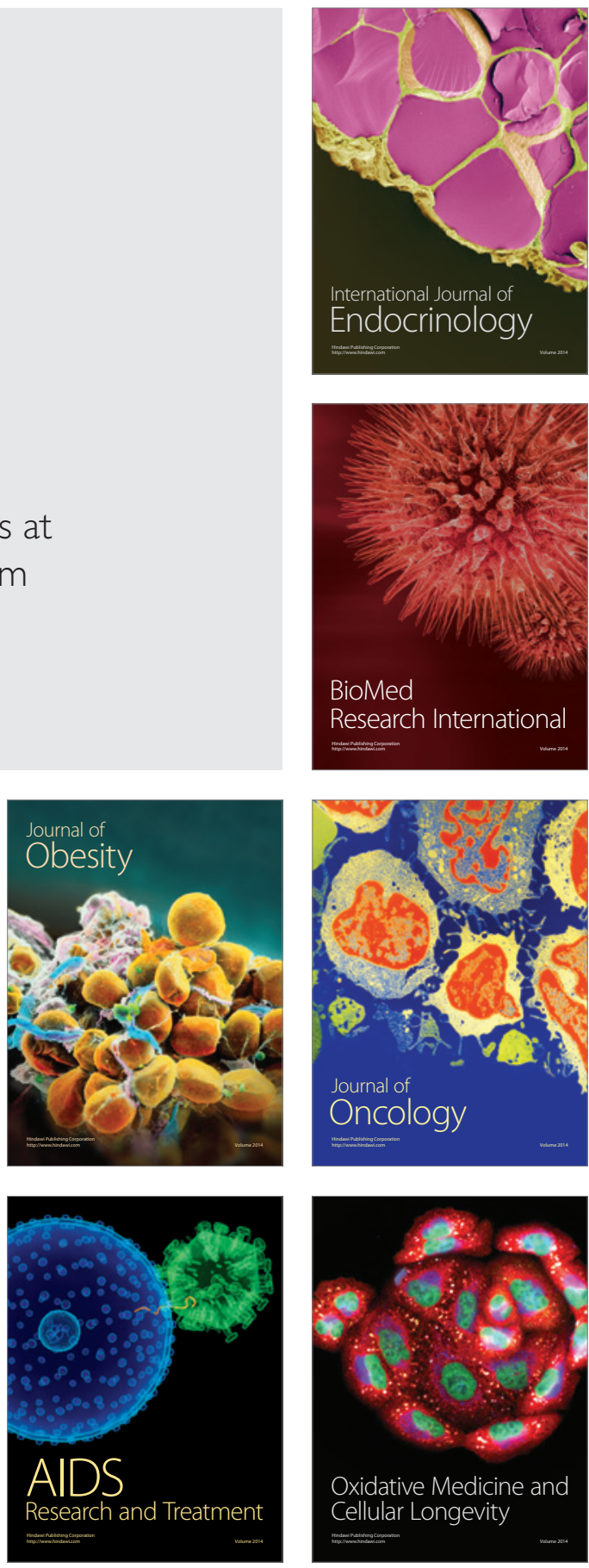